Open Access

\title{
Hand-assisted laparoscopic surgery
} compared with open resection for mid and low rectal cancer: a case-matched study with long-term follow-up

\author{
Xile Zhou', Fanlong Liu', Caizhao Lin', Qihan You², Jinsong Yang ${ }^{3}$, Wenbin Chen ${ }^{1}$, Jiahe Xu', Jianjiang Lin
} and Xiangming $\mathrm{Xu}^{1^{*}}$

\begin{abstract}
Background: This study was designed to compare the long-term surgical outcomes of patients with mid and low rectal cancer after open or hand-assisted laparoscopic surgery (HALS).

Methods: A case-matched controlled prospective analysis of 116 patients who underwent hand-assisted laparoscopic surgery (HALS) for stage I to III mid and low rectal cancer from 2005 to 2010 was performed. Contemporary patients who underwent open rectal surgery were matched to the HALS group at the ratio of 1:1. The perioperative clinical outcomes, postoperative pathology, and survival outcomes were compared between the groups.

Results: The patient characteristics between the two groups were comparable. Ninety patients in the open group and 85 in the HALS group received sphincter-preserving surgery. HALS resulted in less blood loss and wound infection, faster return to oral diet, shorter postoperative hospital stay, and longer operating time. The two groups had similar complication rates. Lymph node retrieval and involvement of circumferential and distal margins were similar for both procedures. Cumulative incidences of locoregional recurrence, disease-free, or overall survival rates were statistically similar.
\end{abstract}

Conclusions: This study suggests that HALS for mid and low rectal cancer is acceptable in terms of short-term clinical outcomes and long-term survival results.

Keywords: Rectal neoplasms, Hand-assisted Laparoscopic Surgery (HALS), Total mesorectal excision

\section{Background}

Recent findings have shown that laparoscopic-assisted proctectomy (LAP) has equivalent survival outcomes compared with open resection for mid and low rectal cancer [1-6]. However, LAP or robotic surgery [7] is limited by the technical difficulties and long steep learning curve, especially in obese patients. Whereas hand-assisted laparoscopic surgery (HALS), a hybrid endoscopic technique incorporating elements of both laparoscopic and open techniques, can overcome these existing limitations.

\footnotetext{
* Correspondence: 2810941796@qq.com

'Department of Colorectal Surgery, the First Affiliated Hospital, College of Medicine, Zhejiang University, 79 Qingchun Road, Hangzhou, Zhejiang 310003, China

Full list of author information is available at the end of the article
}

Since the first report in 1995 [8], HALS has been demonstrated more efficient than standard laparoscopic surgery as far as operating time and conversion rate were concerned [9-13], with oncological clearance comparable to open colorectal resection $[14,15]$. However, to date, little solid evidence exists in support of HALS for mid and low rectal cancer in terms of locoregional recurrence and long-term survival outcomes. Thus, a comparison of HALS versus the open approach for mid and low rectal cancer was performed with long-term follow-up.

\section{Methods}

Between February 2005 and October 2010, consenting patients who underwent HALS for the treatment of mid and low rectal adenocarcinoma $(\leq 12 \mathrm{~cm}$ from the anal 
verge) were prospectively registered. The HALS group was matched against a contemporary open resection series with mid and low rectal adenocarcinoma $(\leq 12 \mathrm{~cm}$ from the anal verge) that declined to undergo HALS or LAP at the ratio $1: 1$ by clinical stage, tumor location, neoadjuvant therapy, gender, age, and body mass index (BMI). Patients with tumor infiltration to the adjacent organs or structures (T4), those with multiple primary colorectal carcinomas, those with familial adenomatous polyposis, those with concurrent distant metastases, those with other malignant diseases, those with recurrent rectal cancer, or those with intestinal obstruction were excluded. This study was approved by the ethics committee of the First Affiliated Hospital, College of Medicine, Zhejiang University.

All patients underwent a physical examination, total colonoscopy plus biopsy. The anesthetist assessed all patients before the operation and assigned an American Society of Anesthesiologists (ASA) grade. Thoracic and abdominal computed tomography (CT) and pelvic magnetic imaging or transrectal ultrasound were performed for preoperative clinical staging. All patients received the same postoperative treatment protocols, including pain control, nutrition support, postoperative rehydration, early ambulation, and early feeding. The discharge criteria included self-feeding, free ambulation, and only mild pain in the wounds.

Patients with low $(0-5 \mathrm{~cm})$ rectal cancers were suggested to receive neoadjuvant chemoradiation if the preoperative TNM stage was stage II or III. Other rectal cancers $(5.1-12 \mathrm{~cm}$ ) were considered selectively based on the extent of the disease. The regimen of neoadjuvant chemoradiotherapy was as follows: 4500 cGy in 25 fractions to the pelvis in 5 weeks and a 540 cGy boost in three fractions to the primary tumor, with oral capecitabine concurrently at a dose of 1000 $1500 \mathrm{mg} / \mathrm{m}^{2}$ per day. The operation was carried out 6-8 weeks after the completion of neoadjuvant treatment by the same surgical team. Postoperative patients with stage III disease received adjuvant chemotherapy.

\section{Surgical techniques}

Seven surgeons (JJL, JHX, WBC, XMX, FLL, XLZ, CZL) performed the operations in the department of Colorectal Surgery at the First Affiliated Hospital of Zhejiang University in the study. Three surgeons (XMX, JJL, WBC) performed the HALS procedures in the study. All three surgeons have extensive laparoscopic experience ( $>50$ hand-assisted laparoscopic colorectal dissections for benign or malignant diseases).

All patients underwent mechanical bowel preparation. All patients underwent total mesorectal excision (TME) with preservation of the hypogastric nerves. For anterior resection, stapled colorectal or handsewn coloanal anastomoses were constructed. An ileostomy was fashioned at the surgeon's discretion, mainly in patients who had undergone neoadjuvant treatment. The loop ileostomy was reversed with stapled anastomosis technique or hand-suture technique when the stapled anastomosis was not feasible 3 months after the curative surgery. An abdominoperineal excision (APE) was performed when it was not possible to obtain a distal margin of more than $1 \mathrm{~cm}$. Some patients aged $>75$ years with comorbidities (diabetes, metabolic disorders, anemia) received Hartmann procedure.

Patients who underwent HALS were placed in the Lloyd-Davis position with forced Trendelenburg $\left(30^{\circ}\right)$. The surgeon, utilizing the left hand for retraction and dissection, stood to the patient's right, whereas the first assistant between the patient's legs. The monitor was placed on the left side of the patient. HALS was started with a small straight abdominal incision in the midline around the umbilicus to place the hand port (Lap-Disc; Ethicon, Guaynabo, Puerto Rico), which was used for the removal of the resected specimen. A pneumoperitoneum was created with a pressure of $12-15 \mathrm{mmHg}$, and two additional trocars were placed: a $10-\mathrm{mm}$ trocar in the suprapubic region for the laparoscope and a 12-mm working port in the lower right quadrant. The using of a third 5-mm trocar in the left was at the surgeon's discretion. Ligation of lymphovascular pedicles and mobilization of the colon and/or rectum was performed intracorporeally along the "Holy plane" down to the pelvic floor. The hypogastric nerves, the pelvic parasympathetic plexus, and the ureters were carefully safeguarded. The lower rectum was transected with endoscopic linear stapler introduced through the right lower quadrant port. Intracorporeal double-stapled colorectal anastomosis technique or handsuture coloanal anatomosis were performed tans-anally. The splenic flexure was mobilized if extra bowel length was needed to facilitate the construction of a tension-free anastomosis.

The open group followed the same oncologic principles as the HALS procedures with a median incision from the symphysis pubis to the navel. Intestinal separation was conducted according to TME principle as in the HALS group.

All specimens were analyzed by experienced pathologists, who assessed harvested lymph nodes, the distal margin involvement (tumor reaching the distal section), and the circumferential margin involvement (a distance of $1 \mathrm{~mm}$ or less from the tumor to the mesorectal fascia).

The sex, age, height, weight, ASA grade, tumor location, and preoperative TNM stage of the patients were recorded, as were operating time, incision length, blood loss, postoperative bowel function, complications, analgesic requirements, length of postoperative stay, and 
pathological information. Short- and long-term complications were recorded using either medical records or by follow-up.

Symptoms of anastomotic leakage were evaluated by digital examination (DE) and proctoscopy followed by abdominal CT scan. Clinical anastomotic leakage was determined by peritonitis, pelvic abscess, abdominal drain discharge of feces or pus, discharge of pus from the rectum, or rectovaginal fistula. CT-enema was performed for suspected patients postoperatively if the anastomotic dehiscence was not detectable by DE.

Locoregional recurrence was defined as reappearance of a tumor in the surgical pelvic field. Locoregional recurrence was confirmed by histological examination. Distant metastases were diagnosed by radiological and/ or histological examination. Further treatments of resection or percutaneous radiofrequency ablation were at the multidisciplinary team's discretion.

\section{Follow-up}

Patients were followed up as outpatients every 3 months within the first 2 years, every 6 months for the next 3 years subsequently, and at 6 months or yearly thereafter. At each visit, they received a physical examination and general blood tests. Every 6 months, they alternated between thoracic and abdominal CT or abdominal ultrasonography and chest radiography. A complete colonoscopy was performed at the 1-year visit.

\section{Statistical analyses}

All data were analyzed by the software package GraphPad Prism 6.02 (GraphPad Software, San Diego, CA, USA) on an intention-to-treat basis. Pearson's $\chi^{2}$-test (or Fisher's exact test when appropriate) and Mann-Whitney $U$ test were performed to compare categorical and numerical data, respectively. Each test was twotailed, and $P$ values $<0.05$ were considered to be significant. The data are expressed as the means \pm standard deviations or numbers with percentages in parentheses unless otherwise indicated.

Survival rates were calculated with the Kaplan-Meier estimation method. Survival curves were compared with the log rank test. For the calculation of disease-free survival (DFS), patients who died without disease recurrence or metastases were censored at the time of death.

\section{Results}

One hundred and sixteen patients who underwent HALS were compared with 116 patients who underwent open rectal resection. The two groups had comparable demographic data (Table 1). The operative results are summarized in Table 2. The rate of sphincter-preserving surgery was similar in the two groups $(P=0.502)$. Defunctioning ileostomy was created in $54.9 \%$ of patients who
Table 1 Patient characteristics

\begin{tabular}{llll}
\hline & $\begin{array}{l}\text { Open } \\
(n=116)\end{array}$ & $\begin{array}{l}\text { HALS } \\
(n=116)\end{array}$ & $\begin{array}{l}P \\
\text { value }\end{array}$ \\
\hline Sex ratio (M/F) & $71 / 45$ & $68 / 48$ & $0.688^{\mathrm{a}}$ \\
Age (years) & $64 \pm 11$ & $61 \pm 16$ & $0.310^{\mathrm{a}}$ \\
Body mass index $\left(\mathrm{kg} / \mathrm{m}^{2}\right)$ & $24.1 \pm 5.0$ & $23.3 \pm 3.1$ & $0.315^{\mathrm{a}}$ \\
ASA grade & & & 0.652 \\
। & $42(36.2)$ & $39(33.6)$ & \\
II & $36(31.0)$ & $45(38.8)$ & \\
III & $33(28.5)$ & $28(24.1)$ & \\
IV & $5(4.3)$ & $4(3.5)$ & \\
Tumor distance from AV (cm) & & & $0.311^{\mathrm{a}}$ \\
0-5 cm & $37(31.9)$ & $30(25.9)$ & \\
5.1-12 cm & $79(68.1)$ & $86(74.1)$ & \\
Preoperative staging & & & $0.861^{\mathrm{a}}$ \\
I & $32(24.1)$ & $30(25.9)$ & \\
II & $41(31.9)$ & $45(38.8)$ & \\
III & $43(33.6)$ & $41(35.3)$ & \\
Neoadjuvant CRT & $33(28.4)$ & $28(24.1)$ & 0.456 \\
\hline ASA Amencan Socm of Aneshesologsts $A V$ Ana & &
\end{tabular}

ASA American Society of Anesthesiologists, AV Anal verge, CRT chemoradiotherapy

aMatched parameters

underwent sphincter-preserving surgery, again with no differences between groups $(P=0.471)$. The morbidity after the closure of loop ileostomy was comparable between groups. Blood loss and wound infection were significantly less in HALS group $(P<0.001$ and $\mathrm{P}=0.015$, respectively). Mean operating time was 34 min longer for HALS than open surgery $(P<0.001)$. Return to oral diet and postoperative hospital stay were longer in the open group $(P<0.001)$. The rates of anastomotic dehiscence, which occurred in eight $(8.9 \%)$ patients in the open group and seven $(8.2 \%)$ in HALS group, did not differ significantly $(P=0.877)$. There was one death $(0.9 \%)$ in the open group due to respiratory infection and multiple organ failure. One death in the HALS group was due to anastomotic dehiscence and subsequent septic shock. There was a similar incidence between the open and HALS groups with respect to chest infection, urinary retention, rectovaginal fistula, urinary fistula, incision hernia, and parastomal hernia. One operation $(0.9 \%)$ in the HALS group was converted to an open procedure. The patient with distal margin involved received a salvage surgery of APE.

Pathological examination data of the specimen were listed in Table 3. Involvement of the circumferential margin and distal margin and the number of isolated lymph nodes were not significantly different between the 2 groups. In the open group for patients with CRM involved, five had locoregional recurrences and three 
Table 2 Operative data and postoperative complications

\begin{tabular}{|c|c|c|c|}
\hline & $\begin{array}{l}\text { Open } \\
(n=116)\end{array}$ & $\begin{array}{l}\text { HALS } \\
(n=116)\end{array}$ & $P$ value \\
\hline Surgical procedure & & & 0.502 \\
\hline Dixon & $90(77.6)$ & $85(73.2)$ & \\
\hline Hartmann & $12(10.3)$ & $18(15.5)$ & \\
\hline APE & $14(12.1)$ & $13(11.2)$ & \\
\hline Anastomosis $^{\mathrm{b}}$ & & & 0.758 \\
\hline Stapled & $82(90.2)$ & $80(94.1)$ & \\
\hline Handsewn & $8(9.8)$ & $5(5.9)$ & \\
\hline Loop ileostomy ${ }^{b}$ & $47(52.2)$ & $49(57.6)$ & 0.471 \\
\hline Morbidity of loop ileostomy closure & $10(21.3)$ & $9(18.4)$ & 0.721 \\
\hline Incision length (cm) & $16 \pm 2$ & $6 \pm 1$ & $<0.001$ \\
\hline Operative time (minutes) & $126 \pm 21$ & $160 \pm 36$ & $<0.001$ \\
\hline Blood loss (ml) & $392 \pm 95$ & $262 \pm 136$ & $<0.001$ \\
\hline Duration of narcotic analgesia(days) & $3.2 \pm 1.2$ & $2.0 \pm 1.1$ & $<0.001$ \\
\hline Return to oral diet (days) & $4.3 \pm 1.6$ & $2.9 \pm 1.5$ & $<0.001$ \\
\hline Length of postoperative stay (days) & $8.5 \pm 2.5$ & $6.5 \pm 2.0$ & $<0.001$ \\
\hline Complications & $36(31.0)$ & $31(26.7)$ & 0.469 \\
\hline Anastomotic leakage ${ }^{b}$ & $8(8.9)$ & $7(8.2)$ & 0.877 \\
\hline Anastomotic bleeding $^{b}$ & $5(5.6)$ & $3(3.5)$ & $0.721^{\mathrm{a}}$ \\
\hline Rectovaginal fistula ${ }^{b}$ & $2(2.2)$ & $2(2.4)$ & $1.000^{\mathrm{a}}$ \\
\hline Wound infection ${ }^{c}$ & $15(12.9)$ & $4(3.4)$ & $0 \cdot 015^{a}$ \\
\hline Chest infection $^{c}$ & $7(6.0)$ & $3(2.6)$ & $0.333^{a}$ \\
\hline Urinary fistula ${ }^{c}$ & $0(0)$ & $2(1.7)$ & $0.498^{\mathrm{a}}$ \\
\hline Urinary retention $^{c}$ & $9(7.8)$ & $6(5.2)$ & 0.423 \\
\hline Intestinal obstruction ${ }^{c}$ & $6(5.2)$ & $11(9.5)$ & 0.208 \\
\hline Incision hernia $^{c}$ & $4(3.4)$ & $1(0.9)$ & $0 \cdot 370^{a}$ \\
\hline Parastomal herniac & $2(1.7)$ & $2(1.7)$ & $1.000^{\mathrm{a}}$ \\
\hline Postoperative death ${ }^{c}$ & $1(0.9)$ & $1(0.9)$ & $1.000^{\mathrm{a}}$ \\
\hline Conversion to open surgery & & 1 & \\
\hline
\end{tabular}

APE Abdominoperineal excision

${ }^{a}$ Fisher Exact test

${ }^{\mathrm{b}}$ Calculated from the operation of Dixon

${ }^{c}$ Calculated from the curative surgery

developed distal metastases. While in the HALS group, the four patients with CRM involved developed both locoregional and distal recurrences.

The duration of follow-up was $63.3 \pm 23.4$ months for the open group and $61.5 \pm 21.9$ months for the HALS group $(P=0.516)$. Locoregional recurrence was similar between groups $(P=0.814)$ (Fig. 1$)$. There were no incision or port sites recurrences. Nineteen patients in the open group and twenty-two patients in the HALS group developed distal metastases. The overall 5-year survival rate was $80.4 \%$ in the open group and $82.6 \%$ in the HALS group $(P=0.617)$ (Fig. 2a). The subgroup survival analysis according to the stage was similar between both groups (Fig. 2b-d). The 5-year DFS rate was $76.4 \%$ in
Table 3 Pathological characteristics after curative resection

\begin{tabular}{|c|c|c|c|}
\hline & $\begin{array}{l}\text { Open } \\
(n=116)\end{array}$ & $\begin{array}{l}\text { HALS } \\
(n=116)\end{array}$ & $P$ value \\
\hline Pathological TNM stage & & & $0.711^{b}$ \\
\hline$C R$ & $1(0.9)$ & $1(0.9)$ & \\
\hline 0 & $2(1.7)$ & $1(0.9)$ & \\
\hline । & $30(25.9)$ & $27(23.3)$ & \\
\hline$\|$ & $46(39.6)$ & $52(44.8)$ & \\
\hline III & 37 (31.9) & $35(30.2)$ & \\
\hline T stage & & & $0.641^{c}$ \\
\hline TO & $1(0.9)$ & $1(0.9)$ & \\
\hline Tis & $2(1.7)$ & $1(0.9)$ & \\
\hline $\mathrm{T} 1$ & $11(9.5)$ & 17 (14.6) & \\
\hline $\mathrm{T} 2$ & $31(26.7)$ & $29(25)$ & \\
\hline $\mathrm{T} 3$ & $71(61.2)$ & $68(58.6)$ & \\
\hline N stage & & & 0.578 \\
\hline No & $79(68.1)$ & $81(69.8)$ & \\
\hline N1 & $17(14.7)$ & $12(10.4)$ & \\
\hline N2 & $20(13.8)$ & $23(12.9)$ & \\
\hline Grade of differentiation & & & 0.687 \\
\hline Well & $12(10.3)$ & $18(15.5)$ & \\
\hline Moderate & $80(69.0)$ & $75(64.7)$ & \\
\hline Poor & $17(1.7)$ & $16(13.8)$ & \\
\hline Mucinous & $5(4.3)$ & $6(5.2)$ & \\
\hline Unknown & 2 & 1 & \\
\hline Isolated lymph nodes & $12.2 \pm 3.5$ & $13.5 \pm 4.6$ & 0.342 \\
\hline CRM & & & $0.374^{a}$ \\
\hline Involved ( $\leq 1 \mathrm{~mm}$ ) & $8(5.4)$ & $4(3.4)$ & \\
\hline Noninvolved (>1mm) & 99 (85.3) & $101(87.1)$ & \\
\hline Missing & 9 & 11 & \\
\hline Distal margin involved ${ }^{c}$ & $0(0)$ & $1(1.0)$ & $1.000^{\mathrm{a}}$ \\
\hline
\end{tabular}

CR Complete response, CRM Circumferential resection margin ${ }^{\mathrm{a}}$ Fisher exact test

${ }^{b} \mathrm{CR}$, TNM stage 0 , and stage I were combined for statistical analysis

${ }^{\mathrm{C}} \mathrm{T0}, \mathrm{Tis}$, and $\mathrm{T} 1$ were combined for statistical analysis

the open group and $74.4 \%$ in the HALS group $(P=$ 0.832) (Fig. 3a), with a subgroup analysis similar, too (Fig. 3b-d).

\section{Discussion}

This study suggested that HALS was associated with less blood loss, faster gastrointestinal recovery, and shorter postoperative hospital stay, without compromise of oncological clearance compared with open laparotomy for mid and low rectal cancer. Notably, the rates of locoregional recurrence, DFS and OS were similar between the two groups through long-term follow-up.

The potential advantages of HALS have been delineated previously in colorectal surgery [14, 16-20]. The 


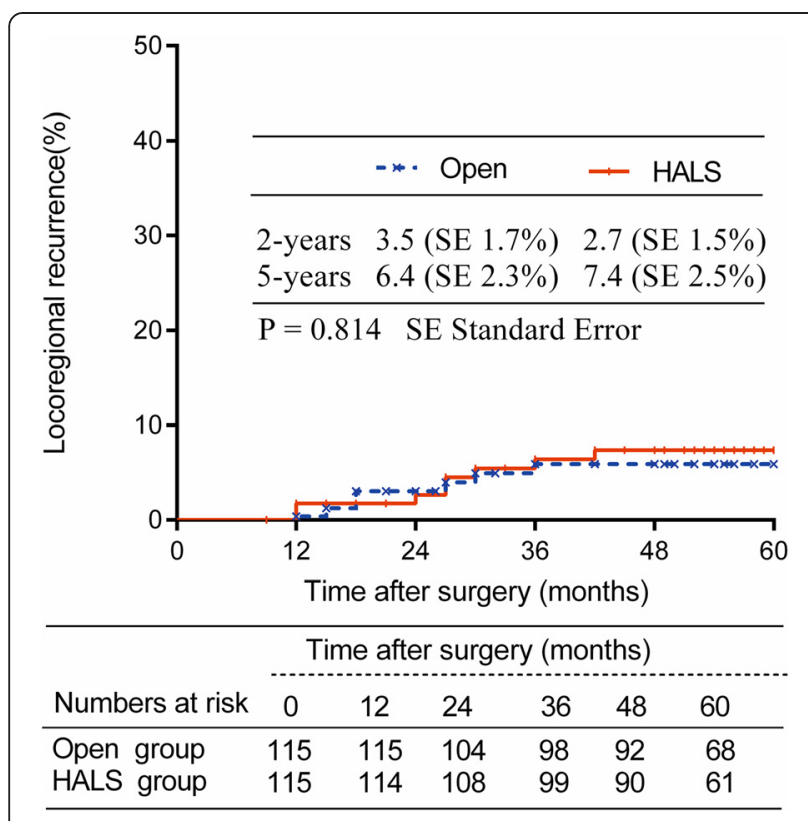

Fig. 1 Locoregional recurrence in Open and HALS groups

HALS Study Group concluded that HALS retained the benefits of minimally invasive surgery and may allow the surgeon to carry out complicated procedures efficiently [18]. Surgeons can easily locate tumors by tactile feedback and decrease iatrogenic injuries. Moreover, the surgeon's left hand inside the abdomen greatly facilitates the placement of the linear stapler and the mobilization of the left colon [21]. Not surprisingly, as a consequence, HALS group resulted in shorter operating time and comparable lengths of hospitalization stay compared with LAP although the incision of HALS was a little bit longer [12]. Furthermore HALS resulted in low conversion rate being varied from 0 to $10 \%$ [15], which was consistent with our data. nevertheless, in published LAP series, the conversion rate to open surgery varied from 1.2 to $29 \%$ (1.2 \% in the COREAN trial [4], $7.5 \%$ in Ng's study [2], $7.9 \%$ in Lujan's study [3], $17 \%$ in the COLOR II trial [22], and $29 \%$ in the CLASICC trial [23]). What is particularly worth mentioning is that the conversion rate of LAP increased with increasing BMI [24]. For obese patients $(B M I>30)$ the conversion rate could reach as high as $31.9 \%$ [24]. Whereas, in a study carried out in Cleveland Clinic in obese patients (BMI > 30), HALS resulted in lower conversion rate compared with LAP (3.5 vs. $12.7 \%$ ). Therefore, Heneghan et al. suggested HALS as a first-line approach for colorectal surgery in obese patients [9]. It also indicated that conversion from LAP to HALS in difficult or complicated cases should be considered to reduce conversion rate to open surgery.

However, HALS port placement and trocar arrangement varies with different surgeons [16-20]. Some authors [17] preferred to place the Gelport in the low midline or Pfannenstiel incision. Our experience showed that midline HALS port placement around the umbilicus greatly facilitated four-quadrant dissection, especially when the splenic flexure mobilization was required. The surgeon's hand in the abdomen greatly facilitates retraction, dissection, and hemostasis. If inappropriate, however, the hand might be cumbersome rather than helpful. In addition to appropriate positioning of the HALS port, correct trocar placement is of vital importance. The principles of instrument triangulation should be adhered to in trocar arrangements. The laparoscope port site may be better when placed in the midline in the suprapubic region allowing views of the entire pelvic area and the whole rectum by adjusting the $30^{\circ}$ lens of the laparoscope, for otherwise, the hand is unable to be helpful and can become a hindrance. Under this protocol, the left side trocar was rarely needed in addition to the working port at the right side.

It is worthy to be noted that HALS surgery cannot decrease the anastomotic leakage rate. Defunctioning ileostomy was required to mitigate the serious sequelae of an anastomotic leak. However, the morbidity after loop ileostomy closure remains high. More recently, tube ileostomy has been performed to avoid the construction of loop ileostomy, and the preliminary results were promising [25-27].

Previous studies and meta-analyses have shown that laparoscopic TME was an oncologically correct technique. The rate of distal and circumferential margin involvement and the number of isolated lymph nodes were reported similar for both laparoscopic and open techniques [28-30]. Nevertheless, data on the number of harvested lymph nodes, positive margin rate, and recurrence rate were seldom reported in HALS study. The pathological data in our study suggested that HALS was oncologically acceptable in the mid and low rectal cancer surgery.

Despite the short-term benefits, the long-term survival outcome of HALS for mid and low rectal cancer was rarely reported, which, however, is mandatory for establishing the value of HALS in the surgical treatment. The short-term benefits of HALS should not be compromised by the incidence of locoregional recurrence and survival. There were discrepancies between LAP and open surgery group for rectal cancer in terms of survival outcomes. In the CLASICC trial, the 5-year OS rates for the rectal cancer patients were not statistically different between the LAP (60.3\%) and open (52.9\%) groups [1]. In the COREAN trial, LAP group provides similar outcomes of three-year DFS as open surgery for locally advanced rectal cancer after preoperative chemoradiotherapy [4]. Lujan et al. [3] reported similar results. These results were in line with our findings. $\mathrm{Ng}$ et al. 


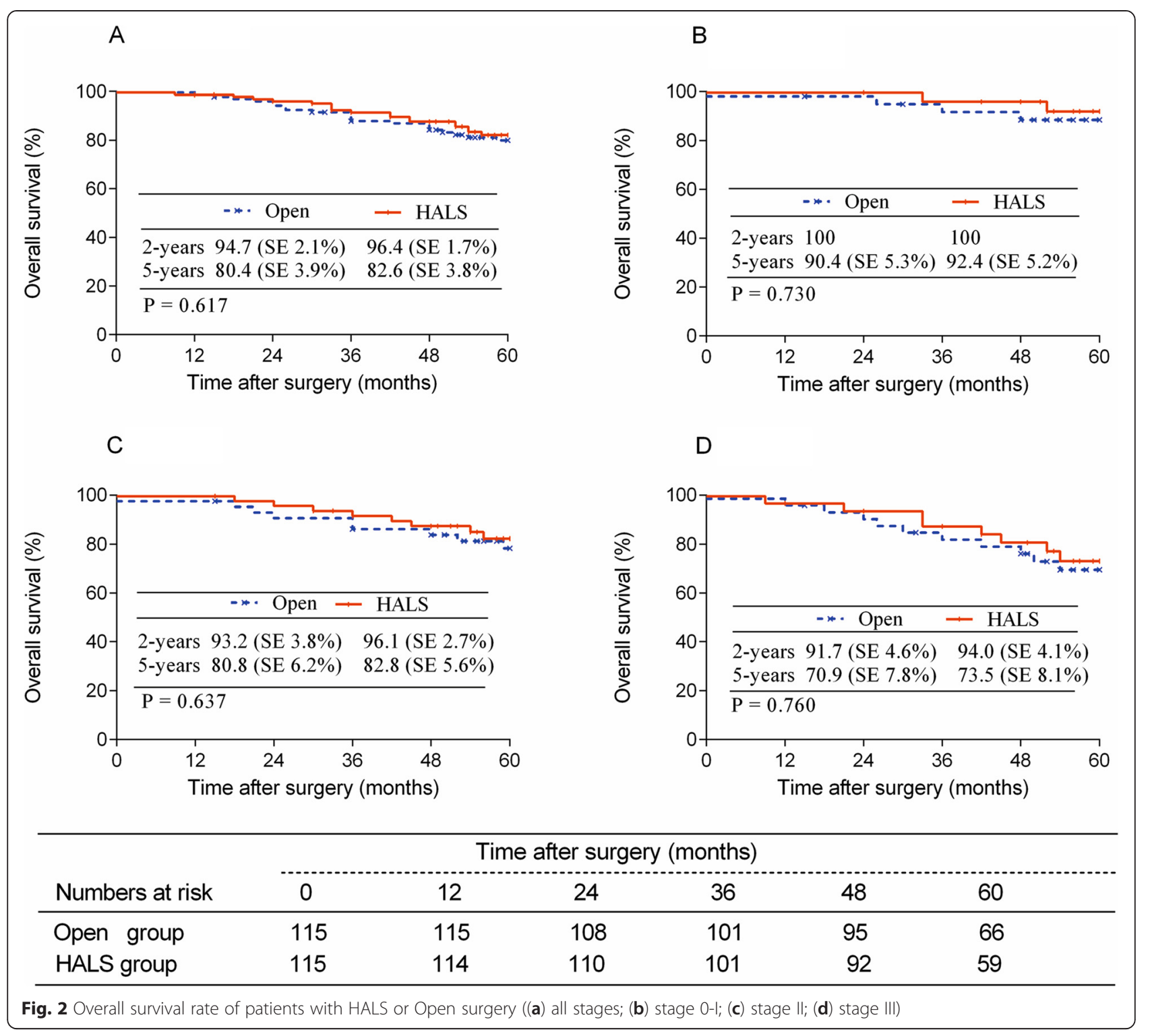

[2] reported that the LAP group had a survival advantage over the open approach. However, its small sample size did not allow convincing conclusion to be drawn.

We must note, however, that HALS technique has limitations. First of all, HALS requires additional use of hand port, which increases the surgical cost and may result in fatigue and numbness of the surgeon's hand in some cases, though some reported that the overall cost was equivalent [31]. Additionally, HALS resulted in longer operative duration, which may be partly owing to the complexity of rectal surgery. The increased handling and mobilization of the bowel was speculated to result in the development of postoperative ileus and intra-abdominal adhesions, whereas in our study, the increased duration is unlikely to cause negative impacts on patients clinically. Moreover, the study was limited by the absence of data concerning genitourinary functional outcomes and non-randomization design. Future welldesigned multicenter studies with more patients are needed to allow a more convincing evaluation, and further comparative study to evaluate HALS vs. LAP for mid and low rectal cancer, especially in obese patients, is also required.

\section{Conclusions}

In conclusion, surgeons now have many different options to achieve a minimally invasive operation for colorectal resection, and our data suggests that HALS for mid and low rectal cancer can improve postoperative recovery, reduces blood loss and postoperative hospital 


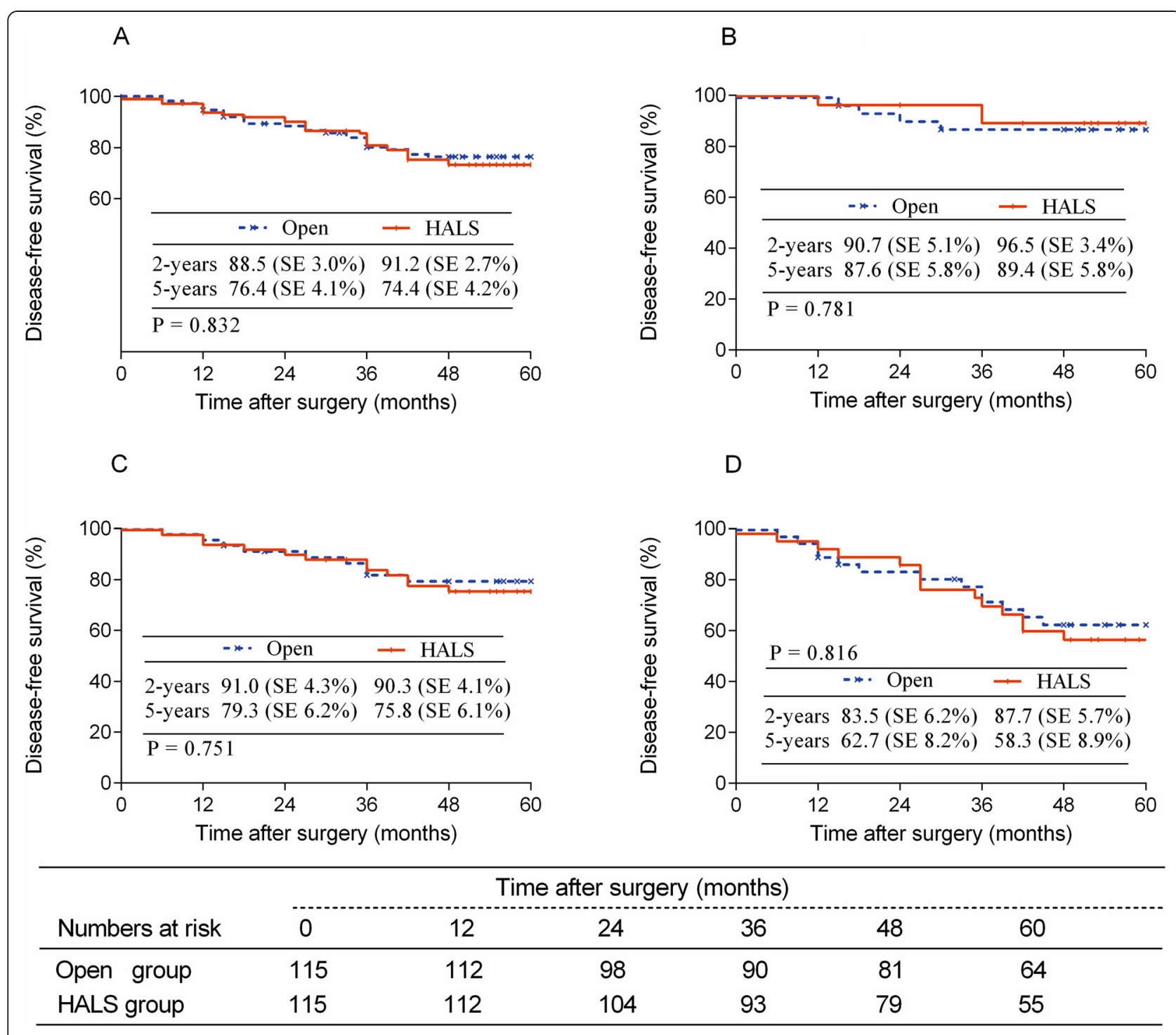

Fig. 3 Disease-free survival rate of patients with HALS or Open surgery ((a) all stages; (b) stage 0-l; (c) stage II; (d) stage III)

stay, and provides similar long-term survival outcomes compared with open laparotomy.

\section{Competing interests}

The authors declare that they have no competing interests.

\section{Authors' contributions}

$X M X, J J L$, and JHX conceived and designed the study. XLZ, CZL, FLL, JSY, and $\mathrm{QHY}$ performed the experiment and contributed the acquisition of the data. XMX and WBC revised the statistical analyses. XLZ wrote the manuscript. All authors read and approved the final manuscript.

\section{Acknowledgements}

The study is supported by the Medicine and Health Science and Technology plan projects in Zhejiang Province in 2015 (2015KYB130). We thank Prof. Limin Du from China Academy of West Region Development, Zhejiang University, for statistical support in this study.

\section{Author details}

'Department of Colorectal Surgery, the First Affiliated Hospital, College of Medicine, Zhejiang University, 79 Qingchun Road, Hangzhou, Zhejiang 310003, China. ${ }^{2}$ Department of Pathology, the First Affiliated Hospital, College of Medicine, Zhejiang University, 79 Qingchun Road, Hangzhou, Zhejiang 310003, China. ${ }^{3}$ Department of Radiation Oncology, the First Affiliated Hospital, College of Medicine, Zhejiang University, 79 Qingchun Road, Hangzhou, Zhejiang 310003, China.

Received: 17 February 2015 Accepted: 28 May 2015

Published online: 10 June 2015

\section{References}

1. Jayne DG, Thorpe HC, Copeland J, Quirke P, Brown JM, Guillou PJ. Five-year follow-up of the Medical Research Council CLASICC trial of laparoscopically assisted versus open surgery for colorectal cancer. $\mathrm{Br} J$ Surg. 2010;97(11):1638-45.

2. Ng SS, Lee JF, Yiu RY, Li JC, Hon SS, Mak TW, et al. Laparoscopic-assisted versus open total mesorectal excision with anal sphincter preservation for 
mid and low rectal cancer: a prospective, randomized trial. Surg Endosc. 2014;28(1):297-306.

3. Lujan J, Valero G, Hernandez Q, Sanchez A, Frutos MD, Parrilla P. Randomized clinical trial comparing laparoscopic and open surgery in patients with rectal cancer. Br J Surg. 2009;96(9):982-9.

4. Jeong SY, Park JW, Nam BH, Kim S, Kang SB, Lim SB, et al. Open versus laparoscopic surgery for mid-rectal or low-rectal cancer after neoadjuvant chemoradiotherapy (COREAN trial): survival outcomes of an open-label, non-inferiority, randomised controlled trial. Lancet Oncol. 2014;15(7):767-74.

5. Ng SS, Leung KL, Lee JF, Yiu RY, Li JC, Teoh AY, et al. Laparoscopic-assisted versus open abdominoperineal resection for low rectal cancer: a prospective randomized trial. Ann Surg Oncol. 2008;15(9):2418-25.

6. Braga M, Frasson M, Vignali A, Zuliani W, Capretti G, Di Carlo V. Laparoscopic resection in rectal cancer patients: outcome and cost-benefit analysis. Dis Colon Rectum. 2007;50(4):464-71.

7. Liao G, Zhao Z, Lin S, Li R, Yuan Y, Du S, et al. Robotic-assisted versus laparoscopic colorectal surgery: a meta-analysis of four randomized controlled trials. World J Surg Oncol. 2014;12:122.

8. Kusminsky RE, Boland JP, Tiley EH, Deluca JA. Hand-assisted laparoscopic splenectomy. Surg Laparosc Endosc Percutan Tech. 1995;5(6):463-7.

9. Heneghan HM, Martin ST, Kiran RP, Khoury W, Stocchi L, Remzi FH, et al. Laparoscopic colorectal surgery for obese patients: decreased conversions with the hand-assisted technique. J Gastrointest Surg. 2013;17(3):548-54.

10. Aalbers AG, Biere SS, van Berge Henegouwen MI, Bemelman WA. Handassisted or laparoscopic-assisted approach in colorectal surgery: a systematic review and meta-analysis. Surg Endosc. 2008;22(8):1769-80.

11. Moloo H, Haggar F, Coyle D, Hutton B, Duhaime S, Mamazza J, et al. Hand assisted laparoscopic surgery versus conventional laparoscopy for colorectal surgery. Cochrane Database Syst Rev. 2010;10:CD006585. doi:10.1002/ 14651858.CD006585.pub2.

12. Tjandra JJ, Chan MK, Yeh CH. Laparoscopic- vs. hand-assisted ultralow anterior resection: a prospective study. Dis Colon Rectum. 2008:51(1):26-31.

13. Ozturk E, Kiran RP, Remzi F, Geisler D, Fazio V. Hand-assisted laparoscopic surgery may be a useful tool for surgeons early in the learning curve performing total abdominal colectomy. Colorectal Dis. 2010;12(3):199-205.

14. Ding J, Xia Y, Liao GQ, Zhang ZM, Liu S, Zhang Y, et al. Hand-assisted laparoscopic surgery versus open surgery for colorectal disease: a systematic review and meta-analysis. Am J Surg. 2014;207(1):109-19.

15. Aalbers AG, Doeksen A, Van Berge Henegouwen MI, Bemelman WA. Handassisted laparoscopic versus open approach in colorectal surgery: a systematic review. Colorectal Dis. 2010;12(4):287-95.

16. Cima RR, Pattana-arun J, Larson DW, Dozois EJ, Wolff BG, Pemberton JH. Experience with 969 minimal access colectomies: the role of hand-assisted laparoscopy in expanding minimally invasive surgery for complex colectomies. J Am Coll Surg. 2008;206(5):946-50.

17. Pendlimari R, Holubar SD, Pattan-Arun J, Larson DW, Dozois EJ, Pemberton JH, et al. Hand-assisted laparoscopic colon and rectal cancer surgery: feasibility, short-term, and oncological outcomes. Surgery. 2010;148(2):378-85.

18. HALS Study Group. Hand-assisted laparoscopic surgery vs standard laparoscopic surgery for colorectal disease: a prospective randomized trial. Surg Endosc. 2000;14(10):896-901.

19. Nakajima K, Lee SW, Cocilovo C, Foglia C, Sonoda T, Milsom JW. Laparoscopic total colectomy: hand-assisted vs standard technique. Surg Endosc. 2004;18(4):582-6.

20. Romanelli JR, Kelly JJ, Litwin DE. Hand-assisted laparoscopic surgery in the United States: an overview. Semin Laparosc Surg. 2001;8(2):96-103.

21. Zawadzki M, Velchuru VR, Albalawi SA, Park JJ, Marecik S, Prasad LM. Is hybrid robotic laparoscopic assistance the ideal approach for restorative rectal cancer dissection? Colorectal Dis. 2013;15(8):1026-32.

22. van der Pas MH, Haglind E, Cuesta MA, Furst A, Lacy AM, Hop WC, et al. Laparoscopic versus open surgery for rectal cancer (COLOR II): short-term outcomes of a randomised, phase 3 trial. Lancet Oncol. 2013;14(3):210-8.

23. Guillou PJ, Quirke P, Thorpe H, Walker J, Jayne DG, Smith AM, et al. Shortterm endpoints of conventional versus laparoscopic-assisted surgery in patients with colorectal cancer (MRC CLASICC trial): multicentre, randomised controlled trial. Lancet. 2005;365(9472):1718-26.

24. Denost Q, Quintane L, Buscail E, Martenot M, Laurent C, Rullier E. Short- and long-term impact of body mass index on laparoscopic rectal cancer surgery. Colorectal Dis. 2013;15(4):463-9.
25. Zhou X, Lin C, Chen W, Lin J, Xu J. Completely diverted tube ileostomy compared with loop ileostomy for protection of low colorectal anastomosis: a pilot study. Colorectal Dis. 2014;16(9):0327-31.

26. Hua H, Xu J, Chen W, Zhou X, Wang J, Sheng Q, et al. Defunctioning cannula ileostomy after lower anterior resection of rectal cancer. Dis Colon Rectum. 2014;57(11):1267-74.

27. Bugiantella W, Rondelli F, Mariani L, Boni M, Ermili F, Avenia N, et al. Temporary percutaneous ileostomy for faecal diversion after intestinal resection for acute abdomen in elderly: how to avoid the conventional loop ileostomy. Int J Surg. 2014;12 Suppl 2:S144-7.

28. Anderson C, Uman G, Pigazzi A. Oncologic outcomes of laparoscopic surgery for rectal cancer: a systematic review and meta-analysis of the literature. Eur J Surg Oncol. 2008;34(10):1135-42

29. Dowdall JF, MCAnena OJ. Long-term results of laparoscopic vs open resections for rectal cancer in 124 unselected patients. Surg Endosc. 2005;19(2):296.

30. Fleshman JW, Wexner SD, Anvari M, LaTulippe JF, Birnbaum EH, Kodner IJ. Laparoscopic vs. open abdominoperineal resection for cancer. Dis Colon Rectum. 1999;42(7):930-9.

31. Maartense S, Dunker MS, Slors JF, Cuesta MA, Gouma DJ, van Deventer SJ, et al. Hand-assisted laparoscopic versus open restorative proctocolectomy with ileal pouch anal anastomosis: a randomized trial. Ann Surg. 2004;240(6):984-92.

\section{Submit your next manuscript to BioMed Central and take full advantage of:}

- Convenient online submission

- Thorough peer review

- No space constraints or color figure charges

- Immediate publication on acceptance

- Inclusion in PubMed, CAS, Scopus and Google Scholar

- Research which is freely available for redistribution

Submit your manuscript at www.biomedcentral.com/submit
C BioMed Central 